\title{
SOCIAL INJUSTICE IN LEARNING OF THE SECOND LANGUAGE AMONG IMMIGRANT CHILDREN IN FINLAND: CONVENTIONAL NARRATIVES AND PERCEPTIONS
}

\author{
Frank Ojwang \\ Faculty of Social Sciences \\ University of Lapland \\ 8 Rovaniemi str., Rovaniemi, Finland, PL 12296101 \\ fojwang@ulapland.fi
}

\begin{abstract}
This is a comparative ethnographic research, comparing the primary school level migrant learners' performance in the learning of the national language of the host countries in Finland and Tanzania. A response from nine teachers, drawn from Tanzanian International Schools, attended by expats' children, was collected through structured interviews. Additionally, two In-Depth Interviews, targeting Tanzanian Swahili teachers at the international schools, was conducted using the narration approach. The study uses MAXQDA to comparatively analyze the findings of fourteen research articles on immigrant pupils' learning challenges of the Finnish language as a second language in Finland, and gathered information from this study's survey is used to analyze the use of Kiswahili as a second language in Tanzania. The research focuses on a comparative analysis of the learning and use of official languages of the host countries as second languages, used in facilitating learning among primary school learners. In Finland, the official language analyzed is Finnish, whereas in Tanzania, the official language analyzed is Kiswahili. The International schools in Tanzania offer Kiswahili lessons to all learners in primary school as guided by national education policy, whereas all public and international schools in Finland offer Finnish lessons for all learners under the education policy. The responses in both Finland and Tanzania are deconstructed qualitatively to illuminate the similarities and differences between European migrant learners and African migrant learners using a second language for learning, and to further deconstruct the nuanced epistemological injustice against minorities. The theories in this research are derived using the grounded theory approach.
\end{abstract}

Keywords: Grounded theory, ethnographic research, Finnish, Kiswahili.

DOI: $10.21303 / 2504-5571.2021 .002063$

\section{Introduction}

Conventional gazes by researchers in the Nordic countries have analyzed the learning trajectories of immigrant pupils in learning the Nordic languages as a second language for learning by immigrant learners in the high north. The cases where the majority studies the minority present a nuanced bias against the African immigrant learners and illuminates epistemological injustice using socially constructed assumptions. The reality however is that children regardless of their race, age and gender, learn at an individual pace, especially where a second language is used as the formal language of facilitating learning.

In Sweden, the education system has served as a model of integration of migrants to the rest of Europe. Nevertheless, the 2016 Program for International Student Assessment [1] survey found out difficulties that migrant students face, in contrast with their native-born classmates. As the report says: “In the 2018/19 school year, Sweden's compulsory education (grundskola) system was expected to accommodate over 1 million students, up from 886000 students in the 2010/11 school year. According to projections by Statistic Sweden, the number of students was expected to rise until at least 2030". Do the European immigrant children learn through the public education systems and as a result, integrate with their peers? The majority of African immigrants join public schools in the Nordic countries including Finland [2].

In Norway, The integration of immigrant children has led to a larger proportion of more heterogeneous students in Norwegian schools. In 2006, 8-10\% of students in Norwegian kindergartens, primary, and secondary schools were of immigrant background, although many were born in Norway. There are more than 120 languages spoken in Oslo schools [3]. According to the OECD, immigrant students who were not born in Norway, especially those who are older and arrive at a 
later stage of their education, face tougher challenges than other students in achieving good education outcomes. But is the situation any different among the European children that migrate to an African country, such as Tanzania that uses Kiswahili as the dominant language of everyday life? Research findings create a national perception of immigrants being inferior without underscoring that this will happen to European children as well if they move to an African country. The tone of the research findings builds a general belief that the African immigrants have learning challenges. A perception that is carried through to their career phase, thus breeding future impediments, is built on perception and believed historically without any epistemic challenges.

The Norwegian report further asserts that compared to their native peers, immigrant students were relatively weaker in their education outcomes on average at all levels of education. At age three, participation rates in early childhood education and care are much lower for immigrant students, although they are comparable at age five. However, the toughest challenges appear to be for first-generation immigrant students (those who were not born in Norway and whose parents were not born in Norway). The researchers observed that as the immigrant learners were nearing the end of lower secondary education, their performance was significantly lower than their native peers.

In Iceland, the research findings revealed that teachers are unsupported in their quest for understanding and managing multicultural education and that the Icelandic school system challenges foreign parents' understanding of school as a traditional place for learning. It is suggested, that addressing the lack of collaboration and discussion between both parties on students' needs and parents' expectations could improve the education of immigrant students [4]. How does the Tanzania education system, especially the international schools support teachers in their quest for understanding and managing multicultural education, involving children from different European and African countries, and from different gender, age and races?

In Denmark, a study showed that the pupils, coming from immigrant background, do far worse at school in natural sciences, reading and mathematics than ethnic Danish pupils. The study further provoked the need to train more teachers in order for them to be able to deal with bilingual pupils [5]. A separate study in Denmark highlighted that teachers reported difficulties, staying in contact with the learners remotely due to the coronavirus pandemic due to their limited access to virtual communication platforms and language barriers [6]. These communication difficulties and the lack of bodily copresence not only made teaching highly challenging, but interrupted their care work, including maintaining daily schedules and facilitating social closeness between learners. Furthermore, the teachers expressed concern about their inability to link and refer the most vulnerable learners to external support services, which were temporarily closed due to the societal lockdown. This study illuminates how COVID-19 induced school closures, constrained the care work of teachers of migrant and refugee learners. The concerns and struggles raised signal the vulnerabilities of African immigrant group of children during times of crisis. How did Covid-19 affect the European immigrant learners in Tanzania? The aggregate epistemic discourse in the Nordic countries presents the immigrant learners as weaker, a perception that is not presented in context with a comparative analysis of how the Nordic children will fair under similar circumstances in foreign contexts like Tanzania. Lack of a fair comparison creates a vacuum for socially constructed perceptions about immigrants, especially the most vulnerable immigrants including Africans.

Like in other Nordic countries, in Finland, the law ensures that all immigrants and asylum seekers who live in Finland and are of compulsory education age (7-18 years) are entitled to the same basic education as Finns. In basic education, pupils of compulsory education age are placed on the grade level that matches their age, knowledge and skills. In addition, remedial teaching in various subjects is provided for newcomers [2].

A study, conducted in Finland by Markku Jahnukainen (2018), revealed that after completing the standardized and highly lauded Finnish comprehensive school (peruskoulu), young people embarked on different educational paths [7]. Even though the Finnish comprehensive school is based on equality, children with an immigrant background find it difficult to integrate into the school system with Finnish pupils and even to gain access to any upper-secondary education. They are more likely to drop out of school than Finnish pupils. This academic trajectory illuminates the 
need to interrogate the quality of education, offered at the Finish comprehensive school, whether it is suitable and quality for the immigrant children.

In 2016, a survey of Finland's teachers showed that the clear majority felt that creating foreign-language enclaves in the Finnish society was experiencing challenges and thus problematic, mostly because it discouraged immigrant-background children from learning Fluent Finnish [8]. According to the survey, conducted by the national broadcaster Yle in collaboration with the teachers' union OAJ, teachers in Finnish schools with a foreign-language population of more than ten percent felt that immigrant children suffered if they did not have enough interaction with Finnish-speaking children and adults. The African immigrants' interaction with Finnish-speaking children is still inadequate for perfecting Finnish among the African immigrant children. In addition, the immigrant children live in bilingual households and often speak a different language at home.

The Yle news survey further reported that the learning of the Finnish language among the Finnish children was affected in immigrant-heavy neighborhoods. The teachers also highlighted that when many students that speak the same language are in the same school, they speak their native or common language when they are together and don't learn Finnish well enough. Many of the teacher survey respondents expressed the desire that no more than one-third of their students would speak a foreign language. This, they say, would best facilitate optimal Finnish language retention among them. With the increase in immigrant children in Finland, the number of immigrants potentially exceed one-third in some schools, especially in the Southern Helsinki region. The teachers surveyed also felt that language skills determined school success. Cultural differences were highlighted as a recurring problem in schools with a strong immigrant population.

Conventional research has illuminated a combination of multiple factors that impact on newcomers' initial education [9]. These include possibilities of establishing friendship with native peers, issues of self-confidence, impact of second generation immigrant peers, the effects of teaching and learning methods, the role of teachers and parents' motivational guidance, and limited places for the organization of the program and its effects. This survey adopts a reverse gaze through the minority, studying the majority, to analyze the expats' children's learning of a second language, being an African language - Kiswahili, and further deconstructs from a minority perspective, comparatively the challenges, faced by African immigrant children versus the expats' children in learning a second language. The interviews narrow down on the expats' children of European descent.

Tanzania children that are native of another language experience challenges in learning Kiswahili, popular as it is in Tanzania. Expats' children, just like African immigrants in Finland, face even more challenges to learn Kiswahili as a second language (L2) due to numerous circumstances among them, low levels of interaction with the native peers, learning in the international school setup that differs significantly in its curriculum content as compared to the public education system, emphasis on the English language as the primary medium of education for facilitating learning and privileged lifestyle that limits exposure to the Kiswahili language and culture through play activities. Unlike African children in Europe that mostly attend public schools, the expats' children attend private prestigious international schools. African families live in normal neighborhoods in Finland, whereas the expat families mostly live in upmarket areas or in much more secured private compounds with limited and regulated entry for non-residents.

International schools in Tanzania are mainly centered on the country's commercial hub Dar Es Salaam city and the northern city of Arusha that houses the East African Community federation and several International NGOs. International schools are predominantly coeducational and use English-medium. The schools range from large, cosmopolitan day schools to small boarding establishments with an emphasis on pastoral support. There are six IB World Schools, which all teach in English. Of these six schools, five are authorized to offer the International Baccalaureate Diploma and four to teach three IB programmes. The latter are the International School of Tanganyika, Dar es Salaam International Academy and the International School Moshi's campuses in Moshi and Arusha [10]. This study collected data from three out of the six international schools in Tanzania.

The Ministry of education in Tanzania does not register International Schools but recognizes schools that have been approved by any of the institutions that register International schools like 
the European Council for International Schools (ECIS) or Association of International Schools in Africa (AISA). Both institutions have set criteria for assessing schools or organizations needs to register with them and membership is awarded only when the registration criteria are met with the applicants. Such international schools must however first be registered as normal schools with the school owners, seeking permit to register an international school [11].

The native African children mostly attend public schools like the majority of native children in Finland. Only few middle-class Tanzanian families attend private schools that offer the same curriculum as the public schools albeit with better infrastructure and enough teachers. There is no accurate data on the number of expats' children that attend international, public or private schools, or that are homeschooling in Tanzania. There is a need to research and have data about education. This study focused on expats' children that attend international schools and learn Kiswahili at the schools. The international schools, attended by expats' children, are elitist in nature and may not entirely be comparable in terms of facilities and curriculum to local public schools in Tanzania. But for this research, the learning of the Kiswahili language is compared to the learning of the Finnish language by the foreign children in Tanzania and Finland respectively. The study limitation is that it could not compare international school learners of a second language in Finland with their peers in Tanzania, as the international schools in Finland did not attract a good number of African immigrant learners. This paper analyzes the social injustice that comes with learning of a second language. Further research should collect data from international schools in other countries where the native language is used as an official language for learning and authority communication nationally.

\section{1. Literature Review}

A rejoinder to the majority, studying the minority, is better achieved through epistemological justice by the minority, studying itself, and the minority, studying the majority. In education, the majority has illuminated a number of findings on the impact of learning a second language by immigrant children. This study analyzes European immigrant children in primary schools to deconstruct the second language learning trajectory outcomes for immigrant children in the Nordic countries as historically illuminated by researchers. This study further draws attention to the starting point in the profiling narratives for building career 'glass ceiling' for African immigrants in Finland.

There are an increasing number of students with different cultural and native language backgrounds in Finnish schools. However, the school system is far from being an all-encompassing multicultural environment for all [12]. According to their study, it was revealed, that in addition to adequate lingual support, fluent co-teaching and co-planning in schools, utilizing school assistants' working time and skills in various and creative ways have turned out to be effective for the learning and social integration of multicultural students. The need for individually planned transitions from preparatory classes to general education also seems to be important. Most of the good practices that teachers mentioned were associated with transplanting the Finnish language and culture onto the 'others'. Scrutinizing the thoughts and attitudes behind these good practices would help to create even better, more multicultural ways of arranging education for cultural diversity, which is inclusive of native Finnish students.

According to a survey by the City of Helsinki, some young people with a foreign background are faced with a wide range of challenges in their lives. Low income levels are more common among immigrant families than native Finnish families. Participation in leisure activities is scarcer and instances of bullying are more common. In addition to this, children and young people with a foreign background more frequently report their general health as being average or worse. This is indicated by a study, conducted by the City of Helsinki Executive Office on the well-being of children and young people with a foreign background. On average, young people with a foreign background are in a more disadvantaged position than their Finnish peers in the transition from comprehensive school. However, the second generation is more likely to attend upper secondary education and obtain a degree. More and more young second-generation immigrants are attending upper secondary school. The majority of children and young people with a foreign background 
enjoy school and feel that they can influence things, related to their schoolwork. However, they report a slightly higher number of difficulties than their peers, and fatigue is more common among comprehensive school pupils with a foreign background [13].

As immigrant pupils are graded on somewhat different grounds or perceptions than Finnish pupils, the differences between immigrant pupils and Finnish pupils were found to be greater in learning results than in grades [14]. This illuminates the potential bias against the immigrant learners that are disadvantaged by the language on their holistic learning versus the grade, scored in the various subjects.

A survey, conducted in 2010, examined the multicultural education discourse in Finland by analyzing the national and municipal curricula for the comprehensive school, educational policy documents and teacher education curricula. The focus was on how multicultural education is talked about and whether it is aimed at all students, or only at immigrant students. The analysis showed that the existing diversity associated with bilingual students, two national churches, and an indigenous population was not considered as part of multicultural education. Instead, cultural diversity is seen narrowly as ethnic, immigrant language and immigrant religious diversity. Multicultural education is therefore only intended for immigrant students [15].

A study illuminated that the learning outcomes in PISA 2012 of immigrant students and Finnish original population were compared. According to the analysis, 15-year-old immigrant students' skills in math, reading, and science were clearly weaker than those of students in the original population, even when the main background factors, such as gender, grade, socio-economic background, home language and age when arriving in Finland, were standardized. Therefore, it is not just the matter of whether immigrants form so-called poor communities, but how the children adjust to the host country and especially its school culture and standards [16].

In Tanzania, scholarly research has illuminated a lot of challenges for native children learning a second language. An analysis of literature illuminates the challenges of Kiswahili in learning. There is little doubt that the systematic but frequently ignored differences between the language and culture of the school and the language and culture of the learner's community have often resulted in educational programmes with only marginal success at teaching anything except self-depreciation [17]. The author asserts that Bilingualism is so complicated a phenomenon that one has the giddy feeling that in speaking of it one speaks of all things at once.

In a Tanzania study, it was observed, that when teachers teach a new subject matter in a language students understand - Kiswahili in this case - teachers also teach new concepts through this language using everyday words they know the students understand. In this way they are expanding the vocabulary of the students in their own language. If the subject teachers try to explain these concepts through a foreign language, they do not know the vocabulary of their students in the foreign language well enough to know whether the students understand the explanations the teacher gives. When concepts are first learnt through a familiar language, they are easy to translate [18].

Scholars acknowledge that one language may have an influence in learning the other language. This influence may be vividly seen in different aspects, such as phonology, morphosyntax as well as lexis. A study focused on investigating how the Ethnic Community Languages (ECL) can phonologically influence the learning process of the Kiswahili language. Kinyakyusa was taken as a sample to represent other ECLs in Tanzania to see its phonological influence in Learning Kiswahili. The study used word lists, in depth interview and observations during data collection. The findings revealed that, phonologically, speech sounds that are similar in Kinyakyusa and Kiswahili as a second language, such as /p/, /t/, /k/, /f/, /s/, were easily learned. Learners were faced with some difficulties in pronouncing some utterances that are not found in Kinyakyusa but exist in Kiswahili. For instance, voiced alveolar trill sound $/ \mathrm{r} / \mathrm{was}$ pronounced as voiced alveolar lateral sound $/ 1 /$, voiceless dental fricative sound $/ \theta /$ was pronounced as voicet less alveolar fricative sound /s/ [19].

Just like in Finland where Finnish is used as the most popular language, or Swedish in Sweden, or Norwegian in Norway, Tanzania uses Kiswahli. It would be considered arrogance of the highest order if Tanzanians were to visit a home of other Tanzanians who speak English rather than Kiswahili or the vernacular to their children. Tanzanians who have been abroad with their families 
would only temporarily use English or any other foreign language before their children pick up Kiswahili or a vernacular language [20].

A retrospective analysis study sought to explain why a group of children who had been matched for English proficiency and socioeconomic status (SES) when they started a school year, and who were subsequently taught and tested through the medium of English, differed in their school achievement at the end of that year. Factors considered include relative productive competence in English morphology, syntax, and vocabulary; verbosity; patterns of social interaction; first language performance; and personality factors. Extensive intra-group variability is reported, but several generalizations are drawn, which have relevance for ESL curriculum organization and instructional practice: vocabulary knowledge is the single most important area of second language (L2) competence when learning content through that language is the dependent variable; grammatical accuracy is of little importance to students' immediate academic needs; communicative competence in social interaction does not guarantee communicative competence in academic situations; and the use of the first language (L1) enhances conceptual development, even when it is tested through the medium of the L2 [21].

A quasi-experimental study was undertaken in 2003 by the LOITASA team in Tanzania on how well students faired when taught in Kiswahili instead of the official LOI, English. The quasi-experimental study was conducted at Nyakato, Rugambwa and Bukoba secondary schools in Bukoba Town and Rural Districts. The findings from the study indicated that most students learnt better when the medium of instruction (MOI) was Kiswahili than when it was English. The best students did even better in Kiswahili while the worst students did even worse when the MOI was English. The gap in performance between students doing better and those doing worse was narrower when Kiswahili was the MOI and wider when the MOI was English. This shows that the use of Kiswahili as MOI promoted greater equality in access to secondary school knowledge while the use of English as LOI promoted and accentuated inequality in access to secondary school education [22].

According to Finland-Africa strategy 2020, the education strategy highlights Intercultural understanding as a key basis for all cooperation, and all operators should have an understanding of the cultural diversity of African countries. The involvement of diaspora communities is considered as integral in the education strategy. In addition, networking between Finland and Africa is considered as key, and the opportunities, offered by digital platforms, must be taken into account (Finnish Government 2020) [23].

Fasold argues that there are three main reasons for choosing a language of instruction: First, do the prospective learners know the language well enough to learn effectively through it? Second, would the proposed choice be consistent with the overall nationalist aims? And finally, are the language itself, the material written in it, and the number of people able to teach in it adequate for the use at the proposed level? [24]. Immigrant learners in both Tanzania and Finland are disadvantaged in the first part, as the official languages, used in facilitating learning, are not the official language of learning.

The Aim of this research is to illuminate the challenges, faced by all individual children, learning a second language for academic purposes regardless of their race, gender, religion, age, geographical location and other factors. The research aims at redirecting the evaluation from a learner-centered evaluation to the teacher-centered evaluation. The evaluation focuses on the effectiveness and efficiency of the learning methodologies and techniques, adopted by the teacher to optimize the use of the second language in learning at school, and to pave way for equitable socio-economic prospects in the future.

\section{Methodology}

The research was conducted between 01 September and 15 December 2020. This period is characterized by resumption of learning activities in Tanzania, following the government declaration of continuation of learning in all schools during the COVID-19 pandemic that was declared as a global pandemic by the World health Organization [25]. Tanzania has five international schools that offer the International British (IB) curriculum and attended mostly by expats' children. The 
Ministry of education in Tanzania does not register International Schools but recognizes schools that have been approved by any of the institutions that register International schools like the European Council for International Schools (ECIS) or Association of International Schools in Africa (AISA).

The researcher sent the link of the self-administered questionnaire to nine teachers. The questionnaire collected qualitative data from the self-administered questionnaire. The questionnaire began with consent statements that had a progression rule when the interviewee acknowledged and gave consent. Two Swahili teachers in Tanzania international schools, selected on the basis of teaching Kiswahili, and with informed consent, were further interviewed using virtual techniques (zoom) to critically elaborate the professional opinion of the learning process and for deductive understanding of the observed and documented experiences during learning of Kiswahili by expats' children in Tanzania. Additionally, the study analyzed findings, drawn from fourteen published articles by Finland-based researchers, and summarized the common findings based on conventional epistemological approaches into four categories in section 4.2. The study factually deconstructs the learning dynamics and relies on measurement of gaze aftereffects as either repulsive or negative [26]. The reported learning of the Finnish language trend is used in analysis and to extrapolate milestones for comparing the fourteen articles' findings with the reverse gaze approach. The reverse gaze anchors on the epistemic injustice arguments, presented by minority scholars in studying the majority. This paper deconstructs the nuanced social injustice and bias motivation behind the fourteen articles' conclusion as viewed by the majority that studies the minority. The approach constantly deflects the reflection onto an African-centric knowledge pool and deconstructs the views objectively for fair reflection of the findings, put into context, using the human rights approach and doing no harm principle.

\section{1. Data Collection procedure}

The data collection was done remotely through a self-administered questionnaire. The respondents were contacted prior and assessed for eligibility to participate in the survey using a preselection questionnaire. The assessment included confirmation that they worked at the international school with European learners present in the classes that they teach or extracurricular activities that they coach. The respondents also confirmed whether they held the teacher position or assistant teacher position, the subject or subjects that they taught and their level of interaction with the European pupils at the school. The researcher then gave the potential respondents a brief overview about the research and the research objectives. All the respondents contacted were recommended by a colleague, serving as a teacher, and thus all the potential respondents, contacted by the researcher, agreed to participate in the survey, having been referred by a colleague. The researcher shared the link to the survey with the participants. The link to the survey included consenting information that the respondents had to accept before participating in the survey. All nine participants gave their consent and completed the survey.

Tanzania is a Kiswahili-speaking country with a generally weak written and spoken English skill even among the teaching fraternity [27]. In order to accurately capture the information, shared particularly by the Kiswahili language teachers, the researcher conducted an in-depth interview with the three Kiswahili teachers that participated in the survey. This was voluntarily advanced on the basis of their participation in the survey, and the researcher made it clear that the aim of the In-Depth Interview (IDI) was to comprehensively understand the learning dynamics of the Kiswahili language among the European pupils. The researcher used a guided set of questions, drawn from the research, but tactfully rephrased to ensure that the information received illuminated the required information gaps. The researcher used a phone interview using WhatsApp call during the IDI and took notes during the discussion. The notes were synthesized and collated to shed more light to the general data, received from the respondents. This also ensured that there was little misinterpretation of the responses, provided in written English. The IDI was done in English and Kiswahili and carried out in a relaxed informal-style conversation for easy relay of information.

\section{2. Data Analysis and Storage}

The self-administered questionnaire data collected was stored anonymously in the google drive of the researcher. In addition, the IDI data was transcribed and stored in the google drive of 
the researcher without any reference to the names or personal information of the respondents. The data handling is fully compliant with the research ethics, EU GDPR regulations and guarantees confidentiality and anonymity of the respondents. Data was entered into the MAXQDA software for qualitative data analysis. The extrapolated summaries are presented in this article. Access to the researcher's storage on google drive is protected using password, only known to the researcher.

The data is analyzed using the mixed methods and bases on grounded theory to formulate the requisite theories and concepts that explain the observations, drawn from the data analysis summary of results. The analysis connects the economic empowerment pathway in the adult years for immigrants in Finland and expats' children in Tanzania.

\section{Results}

\section{1. Participants}

The data was collected from nine teachers, four of whom were male and five females. Out of the nine teachers, three teachers hold the role of assistant teacher and teach the Kiswahili subject to the European minor leaners in the IB system. The study focused on the learners in the elementary level or primary education. Kiswahili is compulsory as a subject for all learners in Tanzanian schools, including the international schools. The research participants were contacted through the existing small network of teachers in international schools in Tanzania. The estimated total number of teachers in the international schools is about 300 from more than 20 countries. The nine respondents represent $3 \%$ of the teaching staff in the five international schools in Tanzania, being a reasonable sample for drawing conclusions in this research. More than $50 \%$ of the teachers interviewed had over 10 years of teaching experience and had taught in more than one international school. Seven teachers taught academic subjects, whereas two teachers taught co-curricular activities. All the international schools are headed by non-native principals. The teachers were contacted by the researcher and given information about the research objectives, before being directed to the online survey instrument that administered a consent clause with confirmation of compliance to the EU GDPR regulations and Research Ethics. The survey allowed participation to respondents that agreed to the consenting information. The online survey was self-administered by the respondents. Data was collected from all nine teachers using the online survey questionnaire. In addition, two out of the three Kiswahili teachers participated in IDIs in order for the researcher to gather an in-depth understanding of the learning trajectory and performance in Kiswahili as a second language by expats' children. The researcher used a structured talking point for the IDIs and documented the responses for further analysis, and for extrapolation of comparable implied and concrete conclusions.

\section{2. Published Articles}

The researcher analyzed fourteen publications that illuminate the learning issues when using Finnish as a second language (S2) by immigrants, including children in Finland, and used the common findings as the basis of analysis in this comparative analysis. The study focused on the comparable indicators to assess the difference, if any, of the learning of a foreign language by an African immigrant child vs an expats' child. Africans were by default referred to as immigrants, whereas immigrants of European descent were referred to as expats, and that is how they are referred to in this paper. The researcher analyzed the following articles and books by scholars for the research conducted in or from Finland;

1. Finland and Singapore, Two Different Top Countries of PISA and the Challenge of Providing Equal Opportunities to Immigrant Students [16]

2. Educational trajectories of immigrant-origin youths in Finland: a mixed methods analysis [28]

3. Immigrant Children, Educational Performance and Public Policy: a Capability Approach [29]

4. Immigrant Student Achievement and Education Policy in Finland [30]

5. Learners with immigrant backgrounds within Finnish education system - Evaluation on the access to education and the support during studies [4]

6. The educational tracks and integration of immigrants - problematic areas and proposals for actions [31] 
7. Teachers' beliefs related to language choice in immigrant students' homes [32]

8. The education of children of immigrants in Finland [33]

9. The discourse on multicultural education in Finland: Education for whom? [34]

10. Migrating pedagogies: Encountering immigrant pupils through movement and dance [35]

11. Segregation, integration, inclusion - the ideology and reality in Finland [36]

12. Does Finnish Educational Equality Extend to Children of Immigrants? [37]

13. Experiences of Finnish teachers working with immigrant students [12]

14. Immigrant Student Achievement and Education Policy: Cross-Cultural Approaches [30]

All the published research articles and books have a consistent narrative flow and pattern from early 2000 to-date, and the trend continues that the research findings are tweaked sentences of the same conclusion. The conclusions were summarized in the following categories;

1. Authority and society perceptions - the fourteen articles underscored a consistent build-up of the perception that the immigrants, especially the most vulnerable minorities were generally weak with a very high potential to drop out of school than the Finnish children. The historical research findings have repeatedly outlined the less-than-Finnish children's interactions using the Finnish language that is believed to play in the disadvantage of the immigrant children. The authority and society perceptions birthed a regularized teacher perception and beliefs about the learners' lower capacity as compared to their Finnish counterparts to master the Finnish language well in the level of fluency and for use in learning. The authorities and society felt that the Finnish deficiency is exacerbated by the use of a different home language in the immigrant households.

2. Lack of equitable quality control on non-Finnish learners - the researcher felt that there is need to have a separate assessment scorecard for immigrants in their formative years of learning to ensure that their capacity is assessed based on their individual learning capacities and knowledge levels. Eleven out of the fourteen articles painted immigrant learners as weak in second language as compared with their native peers. Comparing immigrant children with native Finnish children on the same metric scale breeds social injustice. It presents nuanced systemic injustice and imbalanced comparison scale for 'measuring' the immigrants' learning of the Finnish language. The teachers' grievances on immigrant learners' challenges presents a further imbalanced learning technique for ensuring equitable learning of the Finnish language. Despite offering remedial classes to support the immigrant learners to improve their Finnish language, the regular learning is done using similar learning approaches and techniques. This presents the inequitable nature of learning a second language in the long run.

3. Finnishness vs Internationalization - the education system is engineered to primarily fit into the culture and language of the Finnish society from its inception and thinking, to implementation and execution, with all modifications, aimed at strengthening the Finnishness of the society and less to do with internationalization of education in Finland. Whereas this is commendable, the element of internationalization comes with a set of conditions that include improving the integrated society more equitably and enhancing inclusivity. Seven articles underscored Finnishness in the evaluation and performance of the use of the second language in learning. The teacher, society and authority do not admit inability to enhance equitable learning, but lay the blame on the weakness of the learner and the learners' capacity to be more Finnish. The study noted a consistent one-sided nuanced blame on the learners over highlighting the deficiency in teacher training to cover successful immigrant learning.

4. Epistemological beliefs - all fourteen publications have been anchored on majorities studying minorities, with the knowledge, reserved for knowers that are the majority. The orthodox approaches keep 'whitening' standards, and measures capacity and performance against the European scale. This epistemological approach has created a historical epoch of immigrants' inferiority in learning, affecting their career and life trajectories in the diaspora.

\section{3. Similarities from the analyzed articles and survey}

The common similarities in the learning atmosphere and trajectory by immigrants in Tanzania (Europeans) and Finland (African) are summarized below (Table 1). 
Table 1

A summary of similarities from fourteen articles' conclusions vs Tanzania respondents

\begin{tabular}{|c|c|c|}
\hline Area under review & Immigrant African children in Finland & $\begin{array}{c}\text { Immigrant European children in } \\
\text { Tanzania } \\
\end{array}$ \\
\hline Different geographical location & Different continent from home country & Different continent from home country \\
\hline Different climatic condition & New weather pattern & New weather pattern \\
\hline Different first language & Native African language & European language \\
\hline Age & Minor & Minor \\
\hline Teachers comprise local nationals & Finnish teachers & Tanzanian teachers \\
\hline $\begin{array}{l}\text { Learning trajectory of the second language } \\
\text { is the same }\end{array}$ & $\begin{array}{l}\text { Based on each child's learning pace and } \\
\text { teaching support }\end{array}$ & $\begin{array}{l}\text { Based on each child's learning pace and } \\
\text { teaching support }\end{array}$ \\
\hline $\begin{array}{l}\text { Good learning environment with decent fa- } \\
\text { cilities }\end{array}$ & Good infrastructure & Good infrastructure \\
\hline $\begin{array}{l}\text { Enough teachers to facilitate learning in the } \\
\text { school environment }\end{array}$ & $\begin{array}{l}\text { Good number of teachers in the Finnish } \\
\text { language }\end{array}$ & $\begin{array}{l}\text { Good number of teachers in the Swahili } \\
\text { language }\end{array}$ \\
\hline Decent meals in school & Balanced diet provided for all learners & Balanced diet provided for all learners \\
\hline
\end{tabular}

Whereas there are similarities, we have to note that the European immigrants in Tanzania are accustomed to the good infrastructure and sufficient teacher presence in schools, whereas the African immigrant has to potentially deal with the culture shock of good infrastructure and friendly accessible teaching support. In addition, the difference in weather may be more favorable to the European immigrant children as they get to experience summer 'everyday' of their life, as opposed to the African immigrant child that experiences extreme cold weather for the first time with prolonged darkness of Finland winter.

A European child in Tanzania finds decent and well balanced diet in the international schools in Tanzania. An African immigrant child finds decent balanced diet that was not often the norm in Africa. The majority of schools in Africa do not offer the school feeding program. All fourteen publications and ministry of education information for Finland and Tanzania addressed different aspects of the similarities, and were compared with the data, gathered from the nine respondents.

\section{4. Comparative advantages by Expats' children in Tanzania}

The results from the discussion revealed that there were some comparative advantages that the European immigrant children had in Tanzania over their African peers in Finland. The comparative analysis is summarized in Table 2.

Table 2

Comparative advantages by Expats' children's over African immigrants' children in Finland

\begin{tabular}{ccc}
\hline Area under review & Immigrant African children in Finland & $\begin{array}{c}\text { Immigrant European children in } \\
\text { Tanzania }\end{array}$ \\
\hline Status of household income & Low & High \\
Bullying & Moderate & Low \\
$\begin{array}{c}\text { Transition rate from elementary school to } \\
\text { Institutions of higher learning }\end{array}$ & Low & High \\
$\begin{array}{c}\text { Dignified treatment and respect for hu- } \\
\text { man rights of children }\end{array}$ & Moderate & High
\end{tabular}

It was further observed, that the African immigrant parents suffer from loneliness, considering the social nature of African context, adding to the issues, facing the immigrants' households that are severely neglected. Many African immigrant households transition from growing up in a world, filled with friends and a strong support base, and end up in a world, filled with nameless neighbors and uninterested co-workers. The European immigrant households on the contrary join a community that is hospitable and near-worships them. The Average European immigrant child has more competitive advantage over the average African immigrant in Finland due to the cultural, climatic, health and lifestyle. These play key roles in the holistic learning outcome of the immigrant 
children in Tanzania and Finland. All fourteen publications and ministry of education information for Finland and Tanzania addressed different aspects of the comparative advantages, and these were compared with the data, gathered from the two IDIs in Tanzania.

\section{5. Comparative advantages by African children in Finland}

The researcher analyzed the comparative advantages that African immigrants' children, learning in Finland, have over the European immigrants in Tanzania international school. The parameters for review are summarized in Table 3.

Table 3

African immigrants' children's advantage over Expats' children in Tanzania

\begin{tabular}{|c|c|c|}
\hline Area under review & $\begin{array}{c}\text { Immigrant African children } \\
\text { in Finland }\end{array}$ & $\begin{array}{c}\text { Immigrant European children } \\
\text { in Tanzania }\end{array}$ \\
\hline Wider access to high-tech quality healthcare facility & High & Low \\
\hline Access to peace and political stability & High & Medium \\
\hline Security & High & Low \\
\hline Access to numerous playgrounds and amenities & High & Medium \\
\hline Access to numerous libraries and variety of books & High & Low \\
\hline Quality infrastructure & High & Low \\
\hline
\end{tabular}

The African immigrant children gain a life-transforming change upon migration from Africa to Finland that radically improves their life visibly and rapidly in different spheres of life, regardless of not translating to fair chance in the career phase of life most of the time according to the fourteen articles. The access to quality education (techniques, infrastructure and approaches to learning), improved security, decent housing with accessible and steady supply of clean water among other benefits rapidly transforms the life of an African child and assures the child of improvement in the quality of the childhood phase of life. This may not entirely be the same for a child, moving from Europe, including the Nordic countries, to Tanzania. The quality of life despite living in the upmarket and best neighborhoods cannot be compared to Europe on a holistic scale. The access to quality and high-tech healthcare is restricted to few service providers and specialists in Tanzania, education amenities, including public libraries among others, are not comparable. Despite the demerits, faced by an expats' child in Tanzania, the expats' child still stands a better chance and shot at accessing higher education and securing a clear career trajectory than an African child in Europe. Notice the reference to the European immigrants as 'expatriates', whereas African immigrants regardless of their professional level, retain the immigrant status in Europe. All fourteen publications and ministry of education information for Finland and Tanzania addressed different aspects of the comparative advantages, and these were compared with the data, gathered from the two IDIs in Tanzania.

\section{6. Teaching Credentials and Environment for Tanzania teachers vs Finland teachers}

All the Teachers in Finland have at least a Masters degree level of education. All the Tanzanian teachers, facilitating learning at the International Schools, have a Bachelors degree level of qualification as the basic minimum requirement by the schools. In public schools, it is reported, that best performing students in their high school education can be considered for teaching positions as untrained teachers to help address the teacher shortage in some hardship areas. The Finnish education system promotes collegial and team spirit among its staff. The Tanzania International Schools make a similar effort for collegial and team effort with reservations. A teacher in one of the International schools remarked as follows:

"A Teacher Assistant (local) is not given so much opportunity to grow/ thrive to become a Teacher (expatriate)"

Lack of motivation through equal opportunity to grow is perceived as an injustice against the Tanzanian teacher at the international school as reported by seven respondents. This form 
of injustice creates a toxic work environment over time where the local staff feel discriminated against. A positive work environment is very conducive for learning and nurturing young learners, especially immigrant learners. The dignity, experienced by the Finland teachers, enhances teacher motivation, whereas the secondary position, held by Tanzania teachers, does not compromise on their passion for teaching, as they are still regarded as holding a prestigious position compared to their peers in the public schools.

\section{7. Development milestones}

The two IDIs and one out of the fourteen publications confirmed that the general development milestones, observed in children, are similar with variances as observed elsewhere world over e.g. puberty and age at the first menstrual flow in girls. The children's social development trajectories are similar between children in Finland and Tanzania, regardless of the immigrant background. The children experience changes at the right age, with outliers being early and late maturers noted. The development milestones were analyzed to illuminate any consequence of puberty on learning and performance. The outputs were similar from the teachers' feedback in Tanzania and existing literature concerning immigrants in Finland.

\section{8. Interest in second language and learning trajectory}

Similar trends were reported in the learning of a second language by learners in both Finland and Tanzania. All nine respondents and nine articles highlighted that the learners expressed an interest to learn the language, especially where the learners also used it as the language of play with their friends. Neither gender had a different notable learning trajectory as each and every learner learns a second language in their own way.

All nine Tanzanian teachers felt that it was in the best interest of all Tanzanian children to learn in Kiswahili, being their mother tongue or the closest to their mother tongue as a national language of Tanzania that is widely spoken by all. A sentiment, shared by the Finnish authorities through the use of Finnish in education in the majority of public schools, and highlighted in two articles. Eight Tanzania teachers felt that mixing the European children with local children has a greater potential to improve their learning of the Kiswahili language.

\section{9. Parental involvement in learning a second language}

The parental involvement and interest in a second language faces similar trends in Finland and Tanzania, with less than $50 \%$ of parents sufficiently involved in supporting learning of the second language in both Tanzania and Finland. The parents that are more interested in learning the second language inspired their children to learn the second language, but this also depended on a pupil's learning capacity and strengths. One Tanzania teacher shared that in her opinion, fast learners in either context learnt the second language faster regardless of parental support, the reverse is true for slow learners.

\section{10. Perception of Performance of European children if enrolled in Public schools in Tanzania}

The nine Tanzania teachers felt that the European learners could not perform well academically if enrolled in the Tanzania public schools. The conditions and advanced level of Kiswahili spoken at the schools was well advanced for the European learners to cope and catch up. They felt that the European learners would in essence struggle to catch up and had more than $75 \%$ chance to fail against the Tanzanian pupils if evaluated against similar indicators with Tanzanian children. This is the phenomenon that the scholars have reported about immigrant learners in Finland over the years. There are outliers among immigrants, just like there would be among the European learners, but the majority would trail in the Tanzanian public education system, just like the African immigrants struggle in Finland, especially the first generation immigrant learners. A Tanzanian teacher remarked that "The European children would perform poorly or get absolutely disoriented." This shows how much the situation affects the learners equally in both contexts. 
Two IDI respondents went further to explain that in their opinions, the interest of parents in the Kiswahili language was a prerequisite for the learners to fair better and to accelerate their learning of Kiswahili to a sufficient level for learning. The two respondents also recommended an increase in the number of lessons and hours, dedicated to Kiswahili, if the European children are to improve in their Kiswahili. The two respondents acknowledged that the interaction with local Tanzanian children plays a key role in the learning of Kiswahili among the European children, and further highlighted the need to increase learning methodologies and techniques for accelerated impact by the learners. One of the fourteen published articles shared that Finland offers extra classes for immigrant children that struggle with the Finnish language. The Finnish teaching model integrates different learning methodologies and techniques to facilitate learning with the teacher ratio, taken into account for greater impact. The paper added that the Finnish education system allows a good mix of Finnish and immigrants' children, even though the trajectories take shape as the children advance in age and move to upper classes. Whereas the Finnish education system integrates parents in the learning process, the immigrant parents, especially African immigrant parents are constantly edged out by the language barrier and challenges of attaining a work-life balance.

\section{11. Benefits of learning a second language to the host country}

The nine respondents noted that the few Tanzanian children, learning alongside other international learners, were highly exposed to different cultures and turned out well rounded compared to the other Tanzanian learners in public schools. The international community enriched their awareness about their surrounding and illuminated their sense of globalization compared to the other Tanzanian children that attended school with their neighbors and community members in the local public schools. The Tanzanian children in International Schools are from wealthy family backgrounds. Four out of the fourteen published articles reiterated that Finland equally gains from the internationalization of the education system and society as the Finnish children are more exposed and highly knowledgeable about the international world compared to the earlier generations that learned with fellow Finnish children only. A multicultural, multi-religious and multi-racial class provides a rich pool that is very enriching in understanding the world and learning the world we live in and around us.

\section{Discussion}

The learning trajectory, adopted in teaching a second language, globally cannot be anchored on the evaluation metrics, used by the native children. The expats' children in Tanzania and African learners in Finland, analyzed through data, collected in this study and by researchers through the fourteen articles on immigrant children in Finland, point to the same direction - all children learn a second language in their own way depending on the support systems, social structures, own initiative as well as interests, and learning methodologies, applied through the education system. The expats' children in Tanzania have a low opinion of the Kiswahili language, whereas the African immigrants in Finland hold Finnish in high regard. One of the teachers noted that the expats' children have a low opinion of the African languages and are absolutely reluctant to learn them. The perception of language is important in learning it. African children perceive Finnish language highly as it is the primary language of communication and socializing in Finland, whereas the expats' children in Tanzania hold a low opinion of Kiswahili as they have alternative languages of communication and do not see their dependence on Kiswahili beyond some time frame. This illuminates the social injustice, presented by a second language, based on social perceptions and epistemological foundation.

The planned length of stay in a foreign country determines the desire and need to learn and understand a second language. African children often intend to stay longer in Finland as migration to Finland marks the apex of dreams for many African families. The perception of moving abroad for an African family is access to better services, including education and economic opportunities. European children stay for a short period of time when their parents work in Tanzania, or until they get to the age of majority when they proceed with their further studies outside Tanzania. The temporal nature of their stay, coupled with their perception of Kiswahili, lowers the morale for 
learning Kiswahili as a second language. This underscores the lack of equity in second languages and highlights the social injustice against minority and marginalized immigrants, learning the second language in Finland.

African children's parents, guardians and caregivers focus on economic opportunities and career trajectories with the learning and understanding of the Finnish language. This results in a holistic push for African children to learn Finnish as it influences their socialization with peers, future career trajectory and economic opportunities. On the contrary, for European children in Tanzania, Kiswahili is an added language that does not necessarily influence their career trajectory or economic opportunities, as their opportunities are determined by other factors beyond Kiswahili as a second language. This may be deemed as a privilege that the expats' children of European descent have over African children regardless of the African child in Finland, hypothetically receiving better quality of education and services, all other factors remaining constant. This illuminates the social injustice based on society perception, lack of equitable standards, nuanced blame on the minority learners in their learning of the second language and other epistemological injustice arguments.

Most children, learning a second language, use a different language at home. Multilingualism presents its own set of dynamics in the learning of a second language, and this affects the children in the two countries about similarly, at an individual level. This is equally affected by the age at the time of migration into Finland or Tanzania. An African child that is born in Finland will interact with Finnish earlier compared to a European child born in Tanzania that will interact with Kiswahili a little later. This can be attributed to perceptions and preferences of the parents and social structures of the society. An African family will require the services of a Finnish daycare some or most of the time as compared to a European child in Tanzania. This socio-political dynamic exacerbates nuanced social injustice in the learning of a second language by children.

The majority of social camps, such as summer camps in Finland, are organized in the Finnish language, thus giving the African children limited options to choose from when participating in the summer camp activities. The European children do not experience summer camp or any other camps that are driven by the Kiswahili theme. The summer camps and other camps mix the local Finnish children and immigrants, thus providing a platform where the need for Finnish is highly valuable. There is seldom any camp or socially organized event that brings together European and local Tanzanian children where knowledge of Kiswahili may be critical. This downplays the need and pressure to learn Kiswahili by the European children, learning in Tanzania International Schools. Social injustice against African children thrives through the tactful involvement of the authority to inculcate Finnishness in a holistic aspect of the society. This additionally puts pressure on the learners to learn and use Finnish for their everyday life, unlike their counterparts in Tanzania where the language has a low perception.

The African children in general are perceived to be at the bottom tier of the caste in the Finnish society. The concept of class illuminates the social injustice, practiced in Finland to-date [38]. African immigrants by virtue of the socio-economic engagement fit into the working class. This is exacerbated by the epistemic injustice-engineered opinions and perceptions from studies and articles that portray African immigrant learners as less competitive compared to their Finnish peers. This creates a cyclical history of positioning the African children and future adults at the bottom tier in all aspects of life in the Finnish society. The expats' children of European descent on the other hand hold a privilege position in Tanzania and get a dignified treatment at the International Schools that they attend, and everywhere else that they visit, from supermarket to worship houses, movie theatres to service industry. This shows that neocolonial subtle driven societies continue to affect the Africans and sustain the traumatic cycle of the African race through subtle social injustice, bred from early childhood education.

\section{Theoretical discussion}

This study is anchored on grounded theory and illuminates the underlying factors in the economic trajectories of immigrants in their young adult life. It brings to the fore, the conflict theory by Karl Marx that is often applied to inequalities of gender, social class, education, race, and ethnicity [39]. Karl Marx asserted that all elements of a society's structure depend on its eco- 
nomic structure. Marx maintained that these conflicts appeared consistently throughout history during times of social revolution. These revolutions or "class antagonisms" as he called them, were a result of one class dominating another. Marx described modern society in terms of alienation. Alienation refers to the condition, in which the individual is isolated and divorced from his or her society, work, or the sense of self as is witnessed in Finland by the immigrants. Another idea that Marx developed is the concept of false consciousness. He explained that false consciousness is a condition, in which the beliefs, ideals, or ideology of a person are not in the person's own best interest. In fact, it is the ideology of the dominant class (here, the bourgeoisie capitalists) that is imposed upon the proletariat. Ideas, such as the emphasis of competition over cooperation, or of hard work being its own reward, clearly benefit the owners of industry. Therefore, workers are less likely to question their place in society and assume individual responsibility for existing conditions.

This study underscores the quantitative algorithmic trends of immigrant children's learning trajectory in Finland by different scholars comparatively with expats' children that are their peers in Tanzania. It offers a nuanced revelation on the career trajectory challenges, faced by the immigrants in Finland and other European countries compared to the European children, learning in lesser contexts comparatively speaking. The probability theory that relies on chance is built upon to determine and normalize the trend that otherwise underscores the bias foundation, on which it is rooted. The distinctive feature of such algorithmic games of chance is that the outcome of a given trial cannot be predicted with certainty, although the collective results of a large number of trials display some regularity, in this case in the future prospects of the immigrant learners.

The theories of race and ethnicity are evidently central in South-North migration stories. The three major sociological perspectives of functionalism, conflict theory and symbolic interactionism interplay to illuminate the narrative in immigrant education path and career trajectory linkage. The functionalist perspective to racism discusses the way racism can contribute positively to the functioning of society by strengthening bonds between in-groups members through the ostracism of out-group members. In nuanced ways, the privileged community might increase solidarity by refusing to allow outsiders access to equal opportunities regardless of high standards of education, accessed by the marginalized immigrants compared to their peers, studying in Tanzania. Rose (1951) suggested that dysfunctions, associated with racism, include the failure to take advantage of talent in the subjugated group, and that society must divert from other purposes the time and effort, needed to maintain artificially constructed racial boundaries [40].

Conflict theories are often applied to inequalities of gender, social class, education, race, and ethnicity. Whereas an African immigrant child, learning in Finland with the best pedagogical techniques, quality infrastructure and excellent support system, may be perceived to have the best opportunity, considering the competitive advantage the child gets studying in Finland, the European child, learning in Tanzania, still has a better career prospect and economic opportunities than the African child in Finland. Multiple layers of disadvantage intersect to create the way African children, learning in Finland, experience discrimination, racism and inequality in the education system.

For symbolic interactionists, race and ethnicity provide strong symbols as sources of identity. These three concepts are jointly intertwined in the education trajectory of immigrant children in Finland. The culture of prejudice is written boldly on the walls of classrooms for African children regardless of where they access their education, in Africa or Europe. The education pathway is marred with recognition of their qualification in the tail end if acquired from outside of the global North.

The scholarly materials on immigrant performance in the Finnish education system anchor on the theory of planned behavior by Azjen. The theory states that intentions predict behavior, and intentions are shaped by beliefs [41]. The consistency and repeated conclusions of all scholars, studying immigrants' education pathway, has achieved a normalization and belief that the immigrants for a better part, perform poorly in academics compared to their immigrant peers. A holistic analysis of this conclusion reveals that this is not entirely true if the holistic capacity of a Finnish young adult is anything to go by. The Finnish young adults struggle with depression, drug addiction and carry on the culture of nuanced discrimination, outcomes that should not be synonymous 
with quality education. The immigrants face multiple hurdles and are edged off by the native requirement in the job market and the subtle glass ceiling that hangs in the Finnish society. Given a level playfield, the immigrants would dominate the job market in Finland as they are a community on a mission, a mission to improve their economic situation.

Children, involved in the migration from Africa to Finland, are dependent on the decisions and choices, made by their parents. The epistemological injustice occurs by the majority, studying the minority and choreographing a cycle of low-tier position for immigrants by engineering bias perceptions and normalizing them through an evidence-based approach in favor of the Finnish society. This study illuminates the similarities and glaring inequalities, triggered by race, with other nuanced discriminatory basis, complimenting the education of immigrant children [42, 43].

The limitations in this study include the fact that the researcher could not get a reasonable sample size of Finnish learners in Tanzania that study in Tanzania schools. The researcher however based the research on a sample size, composed of children from European countries that were studying in Tanzania. The comparison was also based on public schools in Finland against international schools in Tanzania. The researcher would have wished to analyze the learners' use of the second language in public schools or international schools in both Finland and Tanzania. The research however narrowed on the learning dynamics of the second language among learners in Finland and Tanzania. Future researchers can explore the nuances in policy as a foundation for systemic social injustice. In addition, further research needs to be conducted on the difficulty in learning a second language by different language groups, such as Nilotes, Bantus, Cushites and others. The same should be explored on European learners from different European language groups to evaluate their learning of a second language.

\section{Conclusion}

The pressure on African children in Finland is glaring and conspicuous. Without the Finnish language, a child is finished. This puts undue pressure on African children to learn the Finnish language and be able to self-integrate socially and in the long run, economically in the labor market and politically for civic participation. The Finnish language is a critical component of the Finnish society and good spoken, listening, reading and writing skills are a prerequisite for learning, especially as one advances in the academic ladder through the Finnish education system. This is critical knowledge for understanding the career and economic trajectory challenges, faced by the African immigrants in finding decent comparable work and optimizing their potential for fair gainful comparable-to-their-Finnish-peers economic opportunities later in life.

Whereas many scholars have written about immigrants challenges in learning Finnish as a second language, and its application in education, the inequitable systemic design, built on social injustice, is hidden, and the immigrants effort to learn Finnish as a second language success is nuanced by such study findings that do not comparatively highlight how the Finnish children would perform under similar circumstances in another foreign country that speaks dominantly a foreign language. When teachers and society understand that the problem is natural and does not only affect immigrants in Finland, the way the challenge is approached will be different. Setting evaluation standards on the teachers' capacity to accelerate understanding and use of Finnish as a second language for learning may flip the coin, with which a second language is evaluated. The evaluation should focus on the teacher and the learning techniques, and not the learner. African immigrant children have no option but to learn the Finnish language, unlike their counterparts in Tanzania that could as well navigate their everyday life without much of a struggle. The expats' children learned Kiswahili in an individualized way based on key determining factors for learning a second language, just like the African children learn Finnish in Finland - individualized pace. Considering the perception, social need of the language for play and learning and future prospects for the language, it is better to conclude that the African learner works four times harder than their European counterpart in the same level. African learners bear the curse of resilience and hard work in learning the Finnish language than their counterparts as the motivation and stakes for learning the Finnish language is higher among the African children. The African societies go beyond the 'midpoint' to integrate the expats, whereas the Finnish society sits their ground for Africans in their 
society to move all the way to them. With the Finland education system declared among the best globally, many African immigrant parents have delegated the learning facilitation function to the teachers. This laissez-faire approach by parents exacerbates the vulnerability of African immigrant learners to acquire knowledge and compete equitably with their peers using the second language.

In conclusion, this paper proves that academics through formal education and world order are systemically designed to maintain the status quo and hierarchies in life through education perception and narrative implants. Finnish children will likely all fail or fair the same when subjected to any form of African epistemic-driven assessment to be used as a metric for evaluating their suitability for learning the Kiswahili language. Education perception needs to be changed to serve as an equalizer for all people regardless of their races, gender and nationality. There is no visible epistemic strategy at scale to equitably address any biases in all spheres of life, including education. This sustains social injustice through second languages, used in learning. This paper projects the epistemic injustice as knowledge remains for knowers in practice and provokes the need to eliminate the status quo through nuanced systemic injustice, institutionalized in developed countries like Finland. Future policy makers and scholars need to offer solutions that eliminate in the long run, institutionalized systemic social injustice that is self-propelling by an engineered nuanced design. There is need to develop and advance the minority episteme in improving knowledge and equally pitch minority studies as epistemic peers in facilitating learning in the different contexts. A tactful approach should be adopted in Finland to change the perception of the society and teachers about immigrants holistically as an effective way to eliminate social injustice.

\section{References}

[1] OECD. 2016. PISA 2015 results (Volume II): Policies and practices for successful schools. Paris: OECD Publishing, 472.

[2] Basic education for immigrants (2021). Ministry of Education and Culture. Available at: https://studyinfo.fi/wp2/en/valintojen-tuki/education-for-immigrants/basic-education-for-immigrants/

[3] Taguma, M., Shewbridge, C., Huttova, J., Hoffman, N. (2009). OECD Reviews of Migrant education: Norway. Paris: OECD Publisher, 76.

[4] Gunnpórsdóttir, H., Barillé, S., Meckl, M. (2018). The Education of Students with Immigrant Background in Iceland: Parents' and Teachers' Voices. Scandinavian Journal of Educational Research, 63 (4), 605-616. doi: http://doi.org/10.1080/00313831.2 017.1415966

[5] Rasch-Christensen, A. (2014). Teachers are not alone in the inclusion task. Dagbladet Information.

[6] Primdahl, N. L., Borsch, A. S., Verelst, A., Jervelund, S. S., Derluyn, I., Skovdal, M. (2020). "It"s difficult to help when I am not sitting next to them': How COVID-19 school closures interrupted teachers' care for newly arrived migrant and refugee learners in Denmark. Vulnerable Children and Youth Studies, 16 (1), 75-85. doi: http://doi.org/10.1080/17450128.2020.1829228

[7] Jahnukainen, M. About transit research. Available at: https://blogs.helsinki.fi/transit-okl/tietoa/transit-tutkimus-nuorten-koulutuspoluista-peruskoulun-jalkeen/about-transit-research/

[8] Finland's teachers: Concentrating immigrants in the same areas creates problems (2016). Yle News. Available at: https://yle.fi/ uutiset/osasto/news/finlands_teachers_concentrating_immigrants_in_the_same_areas_creates_problems/8602698

[9] Djabanor, J. N. (2016). Integration of newly arrived immigrant pupils into schools. Jyväskylä: Jyväskylä University, 79.

[10] Internation Schools in Tanzania. Available at: https:/www.internationalschoolsearch.com/international-schools-in-tanzania

[11] Register a school or a teacher (2016). Ministry of Education - Tanzania. Available at: http://www.moe.go.tz/en/article/registera-school-or-teacher

[12] Sinkkonen, H.-M., Kyttälä, M. (2014). Experiences of Finnish teachers working with immigrant students. European Journal of Special Needs Education, 29 (2), 167-183. doi: http://doi.org/10.1080/08856257.2014.891719

[13] Most of Helsinki's children and young people with a foreign background are well but some face a variety of challenges (2021). City of Helsinki. Available at: https:/www.hel.fi/uutiset/en/kaupunginkanslia/most-of-helsinkis-children-and-young-peoplewith-a-foreign-background-are-well

[14] Kuusela, J., Etelälahti, A. (2008). Maahanmuuttajaoppilaiden oppimistulokset, asenteet ja jatkokoulutusvalinnat perusopetuksen päättövaiheessa. Maahanmuuttajaoppilaat ja koulutus - tutkimus oppimistuloksista, koulutusvalinnoista ja työllistämisestä. Helsinki: Opetushallitus, 97-13

[15] Holm, G., Londen, M. (2010). The discourse on multicultural education in Finland: education for whom? Intercultural Education, 21 (2), 107-120. doi: http://doi.org/10.1080/14675981003696222 
[16] Yeasmin, N., Uusiautti, S. (2018). Finland and Singapore, two different top countries of PISA and the challenge of providing equal opportunities to immigrant students. Journal for Critical Education Policy Studies, 16 (1), $207-237$.

[17] Okonkwo, C. E. (1983). Bilingualism in education: The Nigerian experience re-examined. Prospects, 13 (3), 371-379. doi: http://doi.org/10.1007/bf02220431

[18] Brock-Utne, B. (2006). Teoksessa Focus on fresh data on the language of instruction debate in South Africa and Tanzania, tekijä: Birgit Brock-Utne, Zubeida Desai ja Martha Qorro. Cape Town: African Minds, 19-40.

[19] Mtallo, G. R., Mwambula, H. A. (2018). The Phonological Influence of Ethnic Community Languages in Learning Kiswahili, a Case of Kinyakyusa in Mbeya, Tanzania. Journal of Language Teaching and Research, 9 (4), 702-714. doi: http:// doi.org/10.17507/jltr.0904.05

[20] Malekela, G. A. (2006). Performance in the primary school leaving examination (PSLE): A comparison between Kiswahili and English. Teoksessa Focus on fresh data on the language of instruction debate in South Africa and Tanzania, tekijä: Birgit Brock-Utne, Zubeida Desai ja Martha Qorro. Cape Town: African Minds, 59-68.

[21] Saville-Troike, M. (1984). What Really Matters in Second Language Learning for Academic Achievement? TESOL Quarterly, 18 (2), 199-219. doi: http://doi.org/10.2307/3586690

[22] Galabawa, J. C., Lwaitama, ja A. F. (2003). Complementary Basic Education in Tanzania (COBET). Dar es Salaam: UNICEF.

[23] Young people's comments on Finland's Africa strategy (2020). Finnish Government. Finland Africa strategy. Available at: https://valtioneuvosto.fi/en/-/young-people-s-comments-on-finland-s-africa-strategy

[24] Fasold, R. (1984). The Sociolinguistics of society. Oxford: Basil Blackwell, 292.

[25] World Health Organization. (2020). WHO. Available at: https://www.who.int/director-general/speeches/detail/who-directorgeneral-s-opening-remarks-at-the-media-briefing-on-covid-19---11-march-2020

[26] Seyama, J., Nagayama, R. S. (2004). Eye direction aftereffect. Psychological Research Psychologische Forschung, 70 (1), 59-67. doi: http://doi.org/10.1007/s00426-004-0188-3

[27] Ndulila, E. S., Msuya, ja E. A. (2017). Tanzanian EFL Teachers' Perceptions and Attitudes towards Communicative Language Teaching (CLT): A Case Study of Secondary Schools in Morogoro Municipality, Tanzania. (2017). International Journal on Studies in English Language and Literature, 5 (9), 51-59. doi: http://doi.org/10.20431/2347-3134.0509007

[28] Holmberg, L., Kalalahti, M., Varjo, J., Kivirauma, J., Mäkelä, M.-L., Saarinen, M. et. al. (2018). Educational trajectories of immigrant-origin youths in Finland: a mixed methods analysis. Journal of Education and Work, 31 (7-8), 563-578. doi: http:// doi.org/10.1080/13639080.2018.1549728

[29] Ismail, A. A. (2018). Immigrant Children, Educational Performance and Public Policy: a Capability Approach. Journal of International Migration and Integration, 20 (3), 717-734. doi: http://doi.org/10.1007/s12134-018-0630-9

[30] Klinger, D., Volante, L., Bilgili, O. (2018). Cross-Cultural Approaches to Mitigating the Immigrant Student Performance Disadvantage. Immigrant Student Achievement and Education Policy. Cham: Springer, 197-206. doi: http://doi.org/10.1007/ 978-3-319-74063-8_12

[31] The educational tracks and integration of immigrants - problematic areas and proposals for actions (2016). Helsinki: Ministry of Education and Culture, 44.

[32] Alisaari, J., Sissonen, S., Heikkola, L. M. (2021). Teachers' beliefs related to language choice in immigrant students' homes. Teaching and Teacher Education, 103, 103347. doi: http://doi.org/10.1016/j.tate.2021.103347

[33] Kilpi, E. (2010). The Education of Children of Immigrants in Finland. University of Oxford, 337. Available at: https://ora.ox.ac. uk/objects/uuid:9ae6dfc5-bda6-4d6f-8780-c97abab350e9

[34] Holm, G., Londen, M. (2010). The discourse on multicultural education in Finland: education for whom? Intercultural Education, 21 (2), 107-120. doi: http://doi.org/10.1080/14675981003696222

[35] Anttila, E. (2019). Migrating pedagogies: Encountering immigrant pupils through movement and dance. The International Journal of Critical Pedagogy, 10 (1), 75-96.

[36] Kivirauma, J., Klemelä, K., Rinne, R. (2006). Segregation, integration, inclusion - the ideology and reality in Finland. European Journal of Special Needs Education, 21 (2), 117-133. doi: http://doi.org/10.1080/08856250600600729

[37] Kilpi-Jakonen, E. (2012). Does Finnish Educational Equality Extend to Children of Immigrants?: Examining national origin, gender and the relative importance of parental resources. Nordic Journal of Migration Research, 2 (2), 167-181. doi: http:// doi.org/10.2478/v10202-011-0039-4

[38] Melin, H. (2020). Finland is still a class society. Tampere University. Available at: https://www.tuni.fi/alustalehti/2020/02/21/ finland-is-still-a-class-society/

[39] Marx, K. (1973). The Heritage of Sociology. Chicago: University of Chicago.

[40] Rose, A. (1958). The Roots of Prejudice. UNESCO, 35. Available at: http://unesdoc.unesco.org/images/0007/000733/073342eo.pdf 
[41] Ajzen, I. (1991). The theory of planned behavior. Organizational Behavior and Human Decision Processes, 50 (2), $179-211$. doi: http://doi.org/10.1016/0749-5978(91)90020-t

[42] Nash, M. (1962). Race and the Ideology of Race. Current Anthropology, 3 (3), 285-288. doi: http://doi.org/10.1086/200294

[43] Pirinen, T. (2015). Learners with immigrant backgrounds within the Finnish education system - Evaluation on the access to education and the support during studies. Helsinki: Finnish Education Evaluation Center.

How to cite: Ojwang, F. (2021). Social injustice in learning of the second language among immigrant children in Finland: conventional narratives and perceptions. EUREKA: Social and Humanities, 5, 82-100. doi: http://doi.org/10.21303/2504-5571.2021.002063 